\title{
ETNOMATEMÁTICA VERSUS MATEMAFOBIA
}

\author{
Josenilson de Souza SANTOS \\ Campus Universitário de Abaetetuba/UFPA \\ josenlsoncabano@yahoo.com \\ Sebastião M. S. CORDEIRO \\ Campus Universitário de Abaetetuba/UFPA \\ sebastiao@ufpa.br
}

\begin{abstract}
Resumo: $A$ dificuldade na realidade do ensino-aprendizagem da matemática nas escolas públicas vem crescendo de forma exponencial ao longo dos anos. A caracterização da matemática como ciência exata e abstrata direcionou o processo de ensinoaprendizagem dela a um restrito domínio de técnicas para operar mecanicamente símbolos. A História nos mostra que ela é produto da atividade humana e surgiu da necessidade do homem entender o meio sociocultural em que está inserido. A ideia de abordar a matemática como ciência exata e abstrata, engendrou nos alunos um sentimento de "matemafobia" (medo, aversão, antipatia à matemática). Através de intervenções em algumas escolas públicas de Abaetetuba com oficinas e palestras sobre Etnomatemática em sala de aula, objetivamos despertar os educadores para necessidade de repensar o espaço de sala de aula, buscando transformar alunos em seres críticos, criativos, participativos e transformadores de suas realidades, respeitando suas crenças, costumes e culturas.
\end{abstract}

Palavras-Chave: Etnomatemática. Educação. Matemática. Discente.

Abstract: The difficulty in the reality teach-learning of the mathematics in the schools you publish it comes growing of exponential form throughout the years. The characterization of the mathematics as accurate and abstract science directed the process of teach-learning of the mathematics to a restricted domain of techniques to operate symbols mechanically. History in the sample that the mathematics is product of the activity human being and appeared of the necessity of the man to understand the way sociocultural where is inserted. The idea to approach the mathematics as accurate and abstract science, produced in the pupils a feeling of Matemafobia (fear, aversion, antipatia the mathematics). Through interventions in some public schools of Abaetetuba with workshops and lectures on Etnomatemática in the classroom, we objectify to awake the educators for necessity to rethink the space of classroom, being searched to transform pupils into beings, critics, creative, participativos and transforming of its realities, respecting its beliefs, customs and cultures.

Keywords: Etnomatemática. Education. Mathematic. Student. 


\section{Introdução}

Este trabalho apresenta um projeto de pesquisa bibliográfica e pesquisa de campo na área de Educação Matemática, tendo como perspectivageral detectare mapear as dificuldades noensino-aprendizagem da matemática, nas escolas públicas de ensino fundamental e médio de grande porte do município de Abaetetuba.

Durante a pesquisa constataram-se inúmeros problemas no ensino-aprendizagem da matemática, porém três pontos destacaram-se com maior frequência: deficiência na qualificação dos docentes das séries iniciais; não relacionamento da matemática com a realidade do aluno e a caracterização dela como ciência exata e abstrata pelo professor.

A partir de depoimentos de alunos e professores sobre os fatores que levam ao matemafobismo, buscamos, através da Etnomatemática na sala de aula e da abordagem da matemática coletiva, soluções para melhorar o ensino-aprendizagem da discipliana.

A matemática é produto da atividade humana e surgiu da necessidade do homem conhecer e entender o meio sociocultural em que estava inserido, portanto, não pode ser considerada como ciência exata e abstrata. Ela deve ser vista pelos alunos e educadores como uma ciência que os ajuda a entender o meio coletivo que estão inseridos. Para isso é preciso romper com a ideia de que existe apenas a matemática acadêmica como sendo verdadeira, única e absoluta. Devemos trilhar os caminhos da Etnomatemática, considerando a existência de várias matemáticas em espaços socioculturais diferentes. Os professores devem repensar o espaço de sala de aula, buscando metodologias a partir da realidade dos alunos, transformando a sala de aula em espaço de construção e interação com o meio sociocultural, respeitando suas culturas.

Sabendo da realidade que perpassa a educação no Brasil, como também em nosso estado, é de fundamental importância a busca pela qualidade na prática pedagógica, sendo oportuna uma pesquisa que possa contribuir para mapear os problemas no ensino-aprendizagem deste componente curricular.

\section{Fundamentação teórica}

Para elaborar o projeto de pesquisa bibliográfica, tomamos como referência alguns autores que se dedicam ao estudo da educação 
matemática: Etnomatemática Elo entre a tradição e a modernidade de D'ambrosio (2001); Rangel (1992), com seu livro Educação Matemática e a construção do número pela criança, apoiado por um grande conhecimento da teoria piagetiana, traçou relações da vida escolar do aluno ligado ao meio social; Dienes (1982) verificou que a matemática apesar de ser uma das Ciências Exatas, o significado depende de uma série de fatores sociais. Outras obras que detêm o mesmo ponto de vista de Rangel, foram analisadas cuidadosamente, são elas: Bicudo (1986); Duarte e Castilho (1985); Neto (1998); Giardinetto (1999); além do já citado Dienes (1985).

Os estudos destes autores levam a um único ponto: relacionar a Matemática da sala de aula com a cotidiana, o que fará com que os alunos a compreendam de forma menos problemática. Outros autores como D’Ambrósio (1996), Pessoa, Geverttz e Silva (1979), além de Amaral (1988), discutem que para se aprender matemática esta deve estar relacionada à vida cotidiana, e que foram também consultados com certa precisão. Dessa forma, poder-se-á relacionar o que se defende com outras linhas de pensamento. Identificou-se muito com a investigação a obra de Carraher, Na vida Dez, na Escola Zero (1995), que dá importância à matemática não só na visão de uma Ciência, mas como atividade humana presente praticamente em todas as dimensões da vida social. A definição de Carraher (1995), em relação à aprendizagem da disciplina relacionada com a vida cotidiana, é bem prática, já que sua linha de pensamento engloba desde estudos da Filosofia, Sociologia, Psicologia e finalmente a matemática.

\footnotetext{
A Educação Matemática em especial não se destina a formar matemáticos, mas sim pessoas que possuam uma cultura Matemática que lhe permita aplicar a Matemática nas suas atividades e sua vida diária (MATOS; SERRAZINA, 1996, p. 22-24).
}

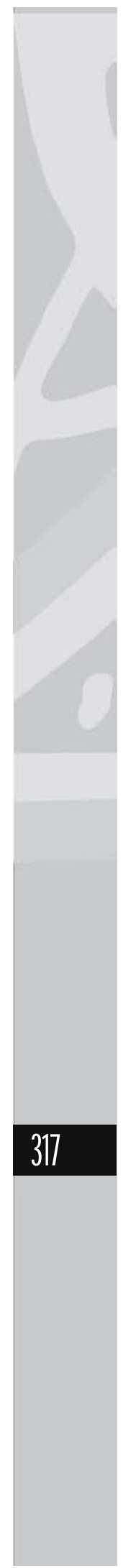

\section{Metodologia}

A metodologia aplicada na elaboração deste projeto de pesquisa inicia-se com o levantamento e a construção de referências bibliográficas sobre o tema em questão para, em seguida, realizar a pesquisa de campo através de entrevistas e depoimentos de alunos e professores do ensino 
fundamental e médio de algumas escolas públicas e de um Cursinho Popular do município de Abaetetuba/Pará. O projeto de pesquisa obedeceu aos seguintes procedimentos:

1. Reconhecimento do local da pesquisa;

2. Coleta de dados através de entrevistas e depoimentos de professore e alunos sobre o ensino-aprendizagem da matemática e os motivos que levam o aluno ao matemafobismo;

3. Intervenção através de palestra sobre Etnomatemática em sala de Aula;

4. Palestra sobre a relevância e a aplicabilidade da matemática no contexto sociocultural dos alunos;

5. Palestra sobre como trabalhar a matemática em sala de aula com grupos de alunos em forma de seminário.

A pesquisa de campo foi realizada nos dias 19, 20 de junho e 27, 28 de agosto de 2009, nos períodos matutino e vespertino, com 12 professores e 360 alunos das $6^{\mathrm{a}}, 7^{\mathrm{a}}, 8^{\mathrm{a}}$ séries do ensino fundamental e $1^{\circ}, 2^{\circ}$ e $3^{\circ}$ anos do ensino médio das escolas Benvida de Araújo Pontes, Basílio de Carvalho, São Francisco Xavier e Cursinho Popular Mendel. A pesquisa usou o seguinte procedimento: coletas de dados em fontes bibliográficas sobre Etnomatemática, depoimento e entrevista com professores e alunos sobre o tema em questão e palestras sobre Etnomatemática na sala de aula e abordagem coletiva da matemática. Os resultados das pesquisas mostraram que são inúmeros os problemas no ensino-aprendizagem da disciplina e inúmeros os fatores que levam o aluno ao matemafobismo. Registramos os depoimentos e entrevistas mais citados por professores e alunos durante a pesquisa de campo.

\section{Resultados}

\subsection{Depoimento de professores}

Falha na formação matemática; professores mal qualificados nas séries iniciais (Antônio Dias; E.E.E.FM.B.A.P). 
Falha na apresentação da matemática; matemática sem sentido nas séries iniciais (Nélio; E.E.E.FM. B.A.P).

Falha no ensino da Matemática; o não relacionamento da Matemática com a realidade (Alcir; E.E.E.FM. B.A.P)

O professor não utiliza uma metodologia dentro da realidade dos alunos (Emerson; E.E.E.FM. B.A.P).

O aluno não presta atenção na aula (Amegrilel; E.E.E.FM.S.F.C).

A matemática é tida como ciência abstrata sem relacionamento com a realidade do aluno (Valdir; E.E.E.F.M.S.C).

A matemática não está presente na realidade (Oziel; E.E.E.F.M.B.C).

\subsection{Depoimento de alunos}

A matemática trabalha muito com a mente; não é igual História e Geografia.

A matemática apresenta muito número e conta.

A matemática tem muita regra.

Não vejo a matemática no meu dia-a-dia.

Tive professores que não souberam ensinar e por isso deixaram traumas de aprendizagem em matemática.

Tenho preguiça mental.

É uma matéria muito difícil, pois apresenta muito cálculo.

Cresci ouvindo as pessoas dizerem que a matemática é um bicho de sete cabeças.

A matemática não servirá para o meu dia-a-dia.

Destacamos alguns dos problemas mais citados na pesquisa entre professores e alunos: deficiência dos docentes das séries iniciais, por isso apresentam uma Matemática sem sentido aos alunos; a disciplina sendo 
abordada como ciência exata e abstrata de difícil entendimento, por isso condiciona o aluno ao desinteresse e, consequente matemafobismo; e a falta de relacionamento da matemática com a realidade dos alunos, criando dessa forma uma espécie de barreira entre o aluno e seu interesse pela disciplina em questão.

O Gráfico abaixo representa os dados da pesquisa sobre os motivos que levam os alunos ao matemafobismo:

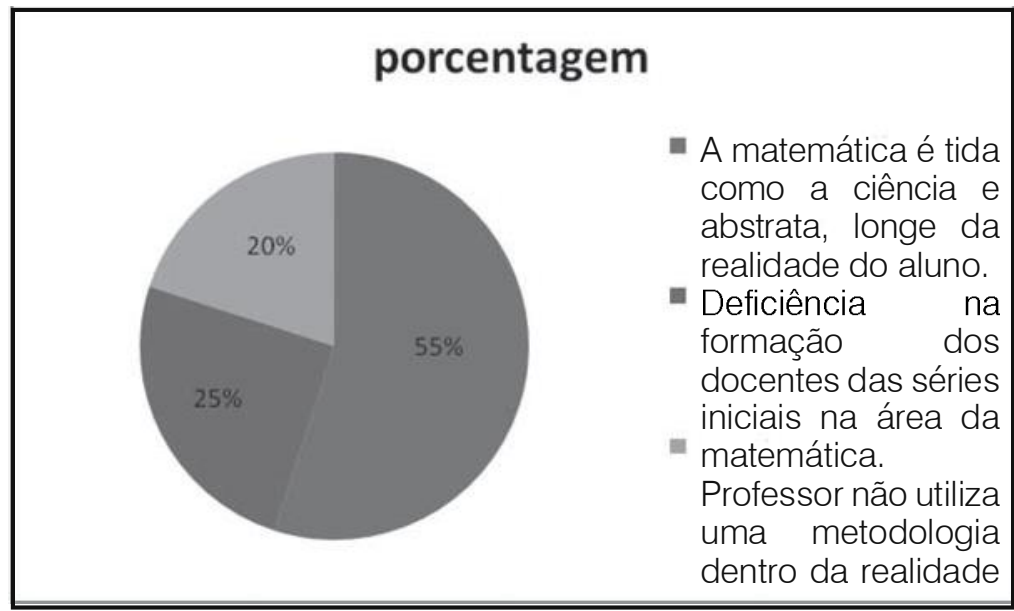

Os dados da pesquisa revelam que o processo didático-pedagógico do ensino nas escolas públicas de grande porte do município de Abaetetuba está indo de mal a pior, por consequência do legado construído ao longo dos anos, com o estudo da mesma voltado para o campo da abstração, esquecendo-se do seu aspecto humano. Isso faz com que o aluno se distancie da disciplina e engendre um sentimento de matemafobia por ela. Em decorrência dos fatos, surgiram ramificações dentro do ensino-aprendizagem neste campo do saber como a Etnomatemática, a modelagem matemática, entre outras.

É preciso dar novos referenciais para os educadores de matemática das séries iniciais e do ensino médio, através de uma matemática que faça sentido e sirva como ferramenta para o aluno entender o meio sociocultural em que está inserido. A ideia de trabalhar o ensino-aprendizagem dessa disciplina de forma abstrata, faz com que ela perca seu verdadeiro sentido como ciência. 
Os Parâmetros Curriculares Nacionais (PCNs) são referências de qualidade para o ensino-aprendizagem nessa área. Sua importância para um potencial matemático é muito grande, pois trazem novos objetivos para a disciplina no Ensino Fundamental como evidenciar os instrumentos que auxiliem a compreender o mundo à sua volta e fazer o aluno vê-la como área do conhecimento que estimula o interesse, a curiosidade, o espírito de investigação e o desenvolvimento da capacidade para resolver problemas.

Partindo dessa realidade, apresentamos propostas para melhorar o processo didático-pedagógico do ensino-aprendizagem nas escolas públicas, através de palestras sobre Etnomatemática na sala de aula e a abordagem didático-pedagógica da matemática de forma coletiva.

\subsection{Etnomatemática}

Dentre os trabalhos que ganharam expressão atualmente, destacase o Programa Etnomatemática, com suas propostas alternativas para a ação pedagógica, tendo seu maior representante o matemático e sociólogo Ubiratan D'Ambrósio. Tal programa contrapõe-se às orientações que desconsideram qualquer relacionamento mais íntimo da matemática com aspectos socioculturais e políticos. Do ponto de vista educacional,

[...] procura entender os processos de pensamento, os modos de explicar, de entender e de atuar na realidade, dentro do contexto cultural do próprio indivíduo. A Etnomatemática procura partir da realidade e chegar à ação pedagógica de maneira natural mediante um enfoque cognitivo com forte fundamentação cultural (D’AMBRÓSIO, 1996, p. 31).

\subsection{Matemafobia}

Para entender melhor a matemafobia é possível dizer que usamos matema para explicar, entender, conhecer, aprender para saber, e fobia para medo, aversão, antipatia.

Ao longo dos anos, a matemática transformou-se em uma disciplina aterrorizante, um verdadeiro bicho de sete cabeças, principalmente na educação básica. Isso ocorreu por consequência dos estudiosos da área 
abordá-la como uma ciência exata, abstrata e distante da realidade. Esse fato engendrou e modelou entre os alunos um sentimento de aversão, medo e até mesmo ódio à disciplina, ou seja, a matemafobia. Não podemos esquecer que a matemática é produto da atividade humana e surgiu da necessidade do homem se organizar enquanto ser social, logo, deve ser encarada como ciência humana.

Ela não pode ser encarada pelos alunos como uma ferramenta de cálculo e voltada para área da abstração. $\mathrm{O}$ ensino-aprendizagem da matemática, através da Etnomatemática, propõe-se a formar seres conscientes de suas realidades, procurando entender o meio sociocultural em que está inserido.

\subsection{A matemática e a construção da cidadania}

A cidadania, além de constituir o sujeito como ser de direitos e deveres para com o Estado, refere-se à inserção das pessoas no mundo do trabalho, nas relações sociais e na cultura. A pluralidade de etnias existente no Brasil dá origem a diferentes modos de vida, valores, crenças e conhecimentos, apresentando-se para a educação matemática como um desafio. Os alunos trazem para a escola conhecimentos, ideias e intuições, construídas através das experiências que vivenciam em seu grupo sociocultural. Eles chegam à escola com diferenciadas ferramentas para classificar, ordenar, quantificar e medir. Além disso, aprendem a atuar de acordo com os recursos, dependências e restrições de seu meio. Para exercer a cidadania, é necessário saber calcular, medir, raciocinar, argumentar, tratar informações estatisticamente etc. Da mesma forma, a sobrevivência numa sociedade que a cada dia se torna mais complexa, exigindo novos padrões de produtividade, depende cada vez mais de conhecimentos. Isso faz com que o profissional se mantenha em um contínuo processo de formação e, portanto, "aprender a aprender" é também fundamental.

Através das pesquisas bibliográficas, podemos perceber que o modelo de ensino-aprendizagem da disciplina em questão ao longo dos anos, teve como referência a matemática abstrata, como única, segura, objetiva e neutra. Em decorrência desses fatos, a matemática acabou perdendo o seu verdadeiro sentido como ciência e despertou no aluno 
um sentimento de medo, aversão e antipatia (matemafobia). Observou-se que a Etnomatemática busca resgatar o verdadeiro sentido da matemática como ciência, transpondo-a do campo da abstração para algo concreto, relacionado com a realidade do aluno, levando em consideração o diaa-dia do aluno a partir de vários referenciais: o meio ambiente, político, sociocultural e até mesmo o emocional. É possível que os professores utilizem o material didático-pedagógico em sala de aula tomando como referência o estudo da Etnomatematica.

A pesquisa de campo revelou, através de depoimentos e entrevistas de professores e alunos das escolas públicas do município de Abaetetuba, alguns fatores que travam e tornam o ensino-aprendizagem caótico, levando o aluno a sentir medo, aversão e antipatia pela disciplina matemática (matemafobia). A ausência de um processo didáticopedagógico matemático voltado para o contexto sociocultural do aluno é peça preponderante nessa engrenagem. Através das palestras nas escolas sobre Etnomatemática na sala de aula e a relevância da matemática no contexto sociocultural do aluno, e ainda sobre a importância de se trabalhar a disciplina em grupo, conseguimos despertar estes alunos e professores para a necessidade da importância da matemática no nosso dia-a-dia, assim como sua aplicabilidade.

Os resultados no ensino-aprendizagem da matemática são mais produtivos quando se trabalhada em grupo, pois há uma maior interatividade entre os alunos e próprio professor, evitando o isolamento na organização de fila indiana. Os professores perceberam que é possível trabalhar a disicplina tomando como referência a Etnomatematica, melhorando o ensino-aprendizagem da mesma, e desconstruindo o legado da matemática como ciência abstrata e longe da realidade em que vivemos.

\section{Considerações finais}

A elaboração do projeto contribuiu de forma significativa para o amadurecimento de reflexões e práticas sobre a educação matemática. A boa receptividade por parte dos professores e dos alunos das instituições de ensino pesquisadas, bem como o interesse dos professores em conhecer e transformar a Etnomatemática em ferramenta didático-pedagógica a ser 
trabalhada em sala de aula, foi o ponto alto desta investigação. Assim, os professores perceberam que a matemática é mais produtiva quando trabalhada em grupo; os alunos observaram que precisam dela para entender o meio em que estão inseridos, além de sua aplicabilidade no cotidiano. A reflexão sobre a origem da matemafobia como produto de um processo didático-pedagógico matemático, criado ao longo dos anos com a caracterização da matemática como ciência exata, abstrata e distante da realidade, levou-nos a perceber que é possível resgatar a imagem da disciplina como verdadeira ciência através da Etnomatemática, e atenuar o sentimento de matemafobismo, melhorando o ensino-aprendizagem da matemática nas escolas públicas do município de Abaetetuba.

\section{REFERÊNCIAS}

BRITO, M.; LUCENA, I.; SILVA, F. Etnomatemática e a Cultura

Amazônica: um caminho para fazer matemática, 2006.

D' AMBROSIO, U. Elo entre as Tradições e a Modernidade. Belo Horizonte: Autêntica, 2001.

MACHADO, J. N. Matemática e Realidade: análise dos pressupostos filosóficos que fundamentam o ensino da Matemática. $5^{\mathrm{a}}$ Ed. São Paulo: Cortez, 2001.

http://velo. Sites.oul.com.br/Ubi.htm. Acesso em 15/06/2009.

http://www. ufpa.br/npadc/gemaz/produção. htm. Etnomatemática e a Cultura Amazônica: perspectiva de inclusão social. Acesso em 10/06/2009.

http://www.ufpa.br/npadc/gemaz/produção.htm. Etnomatemática das Séries Iniciais. Acesso em 10/06/2009. 